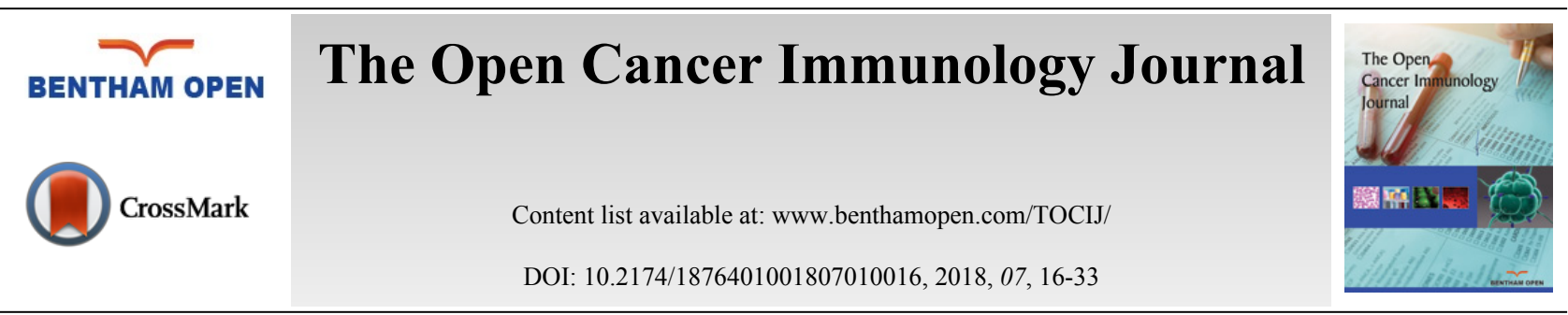

REVIEW ARTICLE

\title{
Myeloid-derived Suppressor Cells in Cancer: A Review on the Pathogenesis and Therapeutic Potentials
}

\author{
Seidu A. Richard \\ Department of Medicine, Princefield University, P. O. Box MA 128, Ho-Volta Region, Ghana, West Africa
}

\begin{abstract}
Myeloid-Derived Suppressor Cells (MDSCs) are multifarious group of immature cells that arise from the myeloid and amass in individuals with cancer, sepsis, burns, or chronic inflammation. It has been evidenced that these group of cells are efficient in modifying adaptive and innate immune responses, coherent with their assumed key biological roles. It is evidenced that MDSCs inter-communicate with Tumor-Associated Macrophages (TAM), Tumor-Associated Neutrophils (TAN), Dendritic Cells (DCs), Receptor for Advanced Glycation End-products (RAGE), Toll-Like Receptors (TLRs), Matrix Metalloproteinase (MMPs) as well as High Mobility Group Box 1 (HMGB1) during carcinogenesis. This interaction although elaborated in various studies and reviews still does not explain in details as to how their interplay results in cancer pathogenesis. We noted that MDSC contributed to cancer immune suppression via TLR-4 receptor and lipopolysaccharideas (LPS). Furthermore, MDSC contributed to cancer development via MMPs (MMP-9 and MMP1-12) as well as RAGE. In the cancer microenvironment, HMGB1-driven MDSC amassment expedites cancer development and metastasis via PMN-MDSCs, macrophages, DCs and Immature Myeloid Cells (IMC). Also, HMGB1 intermediation with MDSCs via RAGE and/or TLR-4 leading to cancer development. Nevertheless, MDSCs have already proven potent in some cancers and are currently been used as treatment options although further studies are needed in some other cancers. Our review, therefore, explores the pivotal pathogenic and therapeutic roles of MDSCs in cancer.
\end{abstract}

Keywords: MDSC, HMGB1, MMPs, RAGE, TLRs, Macrophages.

\section{INTRODUCTION}

Myeloid-derived Suppressor Cells (MDSCs) are multifarious group of immature cells that arise from the myeloid and amass in individuals with cancer, sepsis, burns, or chronic inflammation. It has been evidenced that these group of cells are efficient in modifying adaptive and innate immune responses, coherent with their assumed key biological roles $[1,2]$. Their principal role is to escape or lessen tissue injury during an extreme or a tenacious immune reaction or during inflammation. MDSCs have now been categorized into two distinctive subtypes. These are the monocytic MDSCs and granulocytic MDSCs (M-MDSCs and G-MDSCs) [3].

Studies have shown that the enlargement and stimulation of MDSCs trigger several tumors- or tumor stromal cellderived factors [3 - 5]. One of such factors is tumor-derived Granulocyte-Colony-Stimulating Factor (G-CSF). This factor is principally required for the differentiation of M-MDSCs. Also, tumor-derived Granulocyte-Macrophage Colony-Stimulating Factor (GM-CSF) has demonstrated to partake in M-MDSC generation [3, 6]. Nevertheless, the proportion of G-MDSC to M-MDSC in diverse cancer models is extremely unpredictable and relies on factors that still need further investigation into. Furthermore, in tumor environment, the proportion of G-MDSC and M-MDSC is far lesser than in lymphoid organs. This may have a positive or negative feedback on the immune flora suppression usually seen at the cancer environment. The means via which M-MDSC in tumor environment preferential buildup is still a matter of debate. The potential preferential movement of M-MDSC to the cancer location is postulated to be as result of a flora of chemokines generated by cancer cells. Furthermore, the cancer microenvironment, which is depicted with

* Address correspondence to this author at the Department of Medicine, Princefield University, P. O. Box MA 128, Ho-Volta Region, Ghana, West Africa; Tel: +233508404595; Email: gbepoo@gmail.com. 
hypoxia, low $\mathrm{pH}$ and several other factors which might not sustain subsistence of G-MDSC [1, 2].

In humans, MDSCs are typically outlined as $\mathrm{CD}^{2} 3^{+}, \mathrm{CD} 11 \mathrm{~b}^{+}, \mathrm{HLADR}^{-} / \mathrm{low}$; M-MDSCs are CD14 ${ }^{+}, \mathrm{CD} 15^{-} /$low and G-MDSCs CD14-CD15 $5^{+}$and $\mathrm{CD} 6 \mathrm{~b}^{+}$), coherent with their individual granulocytic and monocytic morphological characters [1, 7]. Studies have evidenced that MDSCs involve dual healing target due to their essential immunomodulatory tasks such as elimination or suppression of hypothetically positive immune response, as seen in tumor or cancer immunotherapy and expansion of endogenous MDSCs seen in conditions in which alteration of the immune responses is advantageous as in the therapy of graft versus host disease or autoimmunity $[1,8]$. It has also been postulated that immature MDSCs infiltrates into a particular cancer microenvironment and can differentiate into TumorAssociated Macrophages (TAM) [3,9]. Therefore, numerous MDSCs has proven to partake in cancer-triggered immunosuppressive actions. On the other hand, averting the expansion of MDSCs is being investigated as an auspicious modality of combating various cancers [3].

It has been evidenced that Programmed cell Death protein 1 (PD-1) receptor is naturally secreted in stimulated T cells 26 and partakes in moderating immune responses [1, 10]. It is also proven that triggered MDSCs and some Antigen-Presenting Cells(APCs) release the PD-1 ligand (PD-L1), which after binding to PD-1 triggers apoptosis in T cells $[1,11]$. Studies have further evidence that IL-6 performances a downregulatory action of IL- $1 \beta$ during inflammatory reactions and because MDSC secretes IL-6R but not IL-1R a direct influence of IL-1 on MDSC is also very possible [12]. These influences which are primarily linked to IL-1 could essentially be triggered by IL-6. Also, IL-1 triggers IL-10 generation via MDSC as well as downregulates IL-12 generation via macrophages [12].

\section{MDSCS IN MICE AND HUMANS}

Primarily, MDSC in mice were outlined as cells of the Gr-11CD11b1 phenotype and deficient in the secretion of markers characteristic of mature Macrophage (MF) and Dendritic Cell (DC) [13, 14]. In humans, however, MDSC were outlined as cells that co-sanitizes mononuclear cells, deficient of markers of lymphocytes, natural killer cells, monocytes, and DC as well as secreted by myeloid cell markers CD33 and CD11b and in some reports, granulocyte markers $[13,15]$. Studies have shown that in mice G-MDSC have a phenotype of CD11b1Ly6G1Ly6Clow, while MMDSC has a phenotype of CD11b1Ly6GLy6Chigh $[15,16]$. The Ly6G molecule is identified to be secreted predominantly on granulocytes while Ly6C is characteristically extremely secreted on monocytes [13, 17]. It is also apparent that Gr-1 antibody (RB6-8C5) can be found on both Ly6G and Ly6C epitopes. Studies have proven that successive grouping with Ly6G, but not with Ly6C-specific antibody, is expressively diminished when Gr-1 antibody is used at the initial phase of staining for MDSC $[13,18]$. In humans however, the phenotype of these cells is less distinctly outlined, though current reports have linked CD15 and CD66b as extra markers permitting the recognition of G-MDSC and M-MDSC [13, 19]. Studies have shown that G-MDSC and M-MDSC vary not only in the morphology and phenotype, but also in the machinery via which they subdue immune function [13, 20]. Therefore, in humans, GMDSC predominantly utilizes Reactive Oxygen Species (ROS) as the contrivance of immune suppression while MMDSC predominantly utilizes upregulation of inducible Nitric Oxide Synthase (iNOS), arginase, and a collection of immune suppressive cytokines to subdue numerous immune functions [13].

\section{MDSCS IN BONE MARROW CELLS}

Studies have shown that Ly-6G and Ly-6C are both markers of primary myeloid extraction obligatory in the downregulation and differentiated of macrophages and DC. In isolation, Ly-6G is upregulated during their advancement into neutrophils $[17,18]$. It is now clear that Ly-6C is extremely released by monocytes in the Bone Marrow (BM) and lowest by BM granulocytes $[18,21]$. The secretion of Ly- $6 \mathrm{C}$ has also been demonstrated on memory CD81 T cells, $\gamma \delta$, $\mathrm{T}$ cells, a subset of NK cells as well as plasmacytoid DC $[18,22]$. Nevertheless, the practical responsibilities of Ly-6G and Ly-6C molecules in the myeloid expansion is still a matter of debate. However, it evidenced that in bone marrow cells Gr-1-specific antibody trigger signaling pathways through STAT1, STAT3, and STAT5, analogous to the consequence of GM-CSF. Thus, Gr-1 antibody triggers myeloid cell development and up-regulation of MF markers [18, 23]. Experimentally, Gr-1 antibody injection had suppressive action on both Gr-1high and Gr-1low MDSC. This practically means that the Gr-1 molecule has some responsibilities in both MDSC function and differentiation. Nonetheless, this further implicates Gr-1 receptor as a natural ligand and a subtype of Gr-1high MDSC which might have conspicuous immune suppressive actions [24].

Additionally, this means that the peculiarities in practical roles of MDSCs and the distinctive quantities of Gr-1 secretion might be considered as differences in the expression of this molecule by G-MDSC and M-MDSC, rather than 
a suggestion that Gr-1 performs a role as a direct marker of cells with immune suppressive actions. Moreover, for eradication of neutrophils, Gr-1 Ab injections also have been utilized in the deplete MDSCs [24].

\section{MDSCS, TUMOR-ASSOCIATED MACROPHAGES AND CANCER}

Macrophages are also a distinct group of myeloid cells that expedites cancer advancement through machineries such as immunological as well as nonimmunological pathways $[25,26]$. Macrophage is morphologically determined via their parochial tissue microenvironment. In the cancer microenvironment, they piquantly differentiate towards an M2-like morphology so they are referred as "Tumor or cancer Associated Macrophages" (TAMs) [25]. TAMs, can be distinguished from M-MDSCs morphologically due to their active secretion of F4/80, minimal-to-transitional secretion of Ly6C as well as minimal or indiscernible secretion of S100A9 protein. Furthermore, IRF8 a marker of terminal macrophage amplifies M-CSF receptor as well as CD115 aid in the expression of TAM as compared to M-MDSCs [26].

Macrophage-specific indicators CD68 and CD163 and minimal or vague secretion of S100A9 can be utilized to distinguish TAM and cancer M-MDSCs in human beings. Studies have evidenced that TAMs facilitate cancer advancement via numerous non-immune machineries such as $\mathrm{f}$ angiogenesis, cancer cell invasion, metastasis, as well as safeguarding cancer cells from chemotherapy-triggered apoptosis [25, 27, 28]. Biologically, macrophages are categorized morphologically into M1-like or classically triggered macrophages and M2-like or alternatively triggered macrophages [25, 29]. It is now clear that M1-like macrophages are characteristically stimulated via lipopolysaccharideas (LPS) as well as IFN- $\gamma$ axis and are depicted with the extraordinary secretion of IL-12 as well as minimal secretion of IL-10. Furthermore, IL-12 facilitates the expansion type $1 \mathrm{~T}$ cell reaction which augments anticancer immunity [25].

It is also well known that M1-like macrophages can eliminate cancer cells while M2-like macrophages are stimulated via glucocorticoid hormones, IL-4, IL-13 as well as IL-10 leading to excessive generation of IL-10 and minimal generation of IL-12 resulting in cancer advancement [25]. Seven morphologically dissimilar macrophage subgroups inside cancers have been found which means that macrophages are multifaceted [25, 26]. Studies have shown that M1-like macrophages that have cancer elimination potentials have similar morphological appearances just like IL- $12^{\text {hi }} \mathrm{IL}-10^{\text {low }}$ and are triggered via LPS and IFN- $\gamma$ axis. Nevertheless, culturing of LPS and IFN- $\gamma$ led triggered peritoneal macrophages and stimulation of cancer MDSC for $16 \mathrm{~h}$ reduced macrophage generation of IL-12 more than $80 \%[25,30]$.

Studies have proven that MDSC-facilitated down-regulation of IL-12 necessitates MDSC-macrophage cell interaction just as MDSC subduction of T cell stimulation [31, 32]. Furthermore, MDSC generates extreme quantities of IL-10 and IL-10 which are strategic cytokine for modifying IL-12 transcription [33, 34]. Nevertheless, Amplified MDSC generation of IL-10 and diminished macrophage generation of IL-12 may influence CD4 ${ }^{+} \mathrm{T}$ cells, Natural Killer (NK) cells and Th2 cells [25]. Moreover, IL-10 champions the differentiation of type 2 CD4 ${ }^{+} \mathrm{T}$ (Th2) cells. On the other hand, IL-12 triggers the differentiation of type $1 \mathrm{CD} 4^{+} \mathrm{T}$ (Th1) cells as well as NK cells. Also, Th2 cells neutralize the expansion of cytotoxic CD8 ${ }^{+} \mathrm{T}$ cells (CTL) as well as the generation of IL-4 which partake in the progress of TAMs $[25,35]$. Studies have demonstrated that MDSC-generation IL-10 may accelerate the advancement of CD4 ${ }^{+} \mathrm{T}$ regulatory cells (Tregs) since IL-10 is an effective trigger of Tregs [34, 36]. It is evidenced that MDSC and macrophage bi-directionally communications also changes macrophage secretion of MHC class II molecules. Furthermore, MHC II reduction necessitates MDSC-macrophage cell-to-cell communication. Trials with IL-10-deficient MDSC suggested that the down-regulation was interceded by IL-10 generated by MDSCs [25].

Several authors have evidenced that NK cells differentiation is depicted with the secretion of CD27 on immature NK cells as well as amplified secretion of CD11b and KLRG-1 as NK cells mature [25, 37]. Nevertheless, in the cancer microenvironment, cancer cells and stromal cells such as MDSC and macrophages, creates a proinflammatory milieu. Also, diverse cancer cells generate multiplicities of pro-inflammatory intermediaries such as IL-6, TNF- $\alpha$, prostaglandins and cyclooxygenases $[25,38]$. Studies have shown that inflammation champions MDSC buildup as well as subdue their effectiveness [31, 39]. Nevertheless, via a feedback mechanism, MDSC generation inflammatory intermediaries which also triggers a downgrade inflammation via the generation of the anti-inflammatory cytokine IL-10 [40]. Also, MDSC extra reduce inflammation by reducing macrophage generation of the pro-inflammatory cytokine IL-6 [39]. This suggests that MDSCs at the inflammatory cancer milieu may be beneficial. 


\section{TUMOR-ASSOCIATED NEUTROPHILS, POLYMORPHONUCLEAR MDSCS AND CANCER}

Tumor-Associated Neutrophils (TAN) are multifarious group of cells with pro-carcinogenic as well as anti-cancer actions [26, 41]. Classification of circulating neutrophils and TANs is founded on features like gradient density, phenotypical roles as well as tissue type [26, 42]. Systematic substantiation on definitive maturation and differentiation phases of the subtypes of neutrophils is still not established. Further studies are needed in this direction. Terminologies like anti-tumorigenic N1 and pro-tumorigenic N2 mouse neutrophils were introduced to depict distinctive groups of TAN [41]. Recently, polymorphonuclear (PMN)-MDSCs which are a subset of MDSCs have been identified. The exact difference between TAN and PMN-MDSCs is still a matter of debate because both cells have similar morphological appearances [26].

Most researchers used the terminology 'granulocytic MDSC' to depict PMN-MDSC, but it is now clear that the latter terminology well depicts this MDSC subset, because PMN-MDSC is morphologically different from steady-state neutrophils. PMN-MDSC have fewer granules, distorted buoyancy, decreased CD16 and CD62L, and amplified arginase 1, peroxynitrite, CD11b as well as CD66b) [26]. PMN-MDSC and TAN can be distinguished from mononuclear cells within the $\mathrm{CD} 11 \mathrm{~b}^{+}$myeloid cell segment because of their secretion of Ly6G granulocytic cell marker in mice. On the other hand, eosinophils can be identified based on their secretion of sialic acid-binding immunoglobulin-like lectin F [43].

Morphologically, TAM can be differentiated from M-MDSCs because of their amplified secretion of F4/80, minimum-to-intermediary secretion of Ly6C as well as minimum or unnoticeable secretion of S100A9 protein. Furthermore, IRF8, an indicator of terminal macrophage differentiation amplifies M-CSF receptor and CD115 resulting in the expression of TAM compared to M-MDSCs [26]. It is very difficult to distinguish neutrophils from PMNMDSCs because these cells share similar morphological features. It is, however, possible to distinguish between them using functional tests. It is now clear that macrophage-specific indicators like CD68 and CD163, together with minimal or deficient secretion of S100A9 can be utilized in distinguishing TAM from cancer M-MDSCs in humans [43]. However, the glitches in differentiating cancer PMN-MDSCs from TAN are the same as in mice. There are currently no clear cell-surface indicators that can directly to use to distinguishing of TAN from PMNMDSCs.

\section{MDSCS, DENDRITIC CELLS AND CANCER}

Dendritic Cells (DC) are cells that process and present antigen for the stimulation of $\mathrm{CD}^{+}$as well as $\mathrm{CD} 8^{+} \mathrm{T}$ cells [25]. It is evidenced that the quantities of mature DC diminished equitably with rising quantities of MDSC in an in-vitro investigation utilizing mouse MDSC differentiated from c-kit ${ }^{+} \mathrm{BM}$ progenitor cells in the presence of IL-4, GM-CSF, and PGE2 [44]. A study revealed that IL-10 generated by hepatocellular carcinoma-triggered MDSC resulted in reduced DC generation of IL-12 [45]. The decrease in mature DC as seen in cancer individuals is because of distortion in MDSC/DC progenitor cells towards the preferential differentiation of MDSC at the expense of DC. This distortion occurs because MDSC and DC share a common progenitor cell [44].

Studies with MDSC from melanoma individuals revealed that MDSC compromised DC maturation via the diminishing of antigen uptake, aversion of movement of immature and mature DC, inhibiting DC triggering of IFN- $\gamma$ generation of $\mathrm{T}$ cells as well as distortion of DC cytokine generation towards anti-inflammatory kinds [46, 47]. Furthermore, DC generation of pro-inflammatory cytokine IL-23 and its down-regulatory triggering of Th17 cells may contribute to the consequences of MDSC on DC. Therefore, IL-23 and IL-17 facilitate cancer advancement and MDSC may decrease cancer advancement by restraining IL-23 and IL-17 generation [47].

\section{MDSCS, TOLL-LIKE RECEPTORS AND CANCER}

Toll-Like Receptors (TLRs) have a fundamental responsibility in the stimulation of innate immune responses. It is evidenced that signaling via TLR-4 characteristically comprises of the bonding of LPS to the LPS bonding protein, which consequently relocates LPS to the membrane-bound receptor CD14 [25]. It is also now clear that MDSCmacrophage inter-communication utilizes LPS. LPS has also been confirmed as a stimulate of macrophages [48]. A study has shown that CD14 inter-communication with TLR-4 to triggers TLR-4 signaling as well as down-regulatory triggering of NF- $\mathrm{KB}$ [48] (Fig. 1). Studies have proven that CD14 concentrations are amplified on inflammatory MDSC during inter-communication with macrophages. This amplification is TLR4-dependent since TLR4-deficient inflammatory MDSC do not exhibit raised concentrations of CD14 (Fig. 1) [39, 49]. 


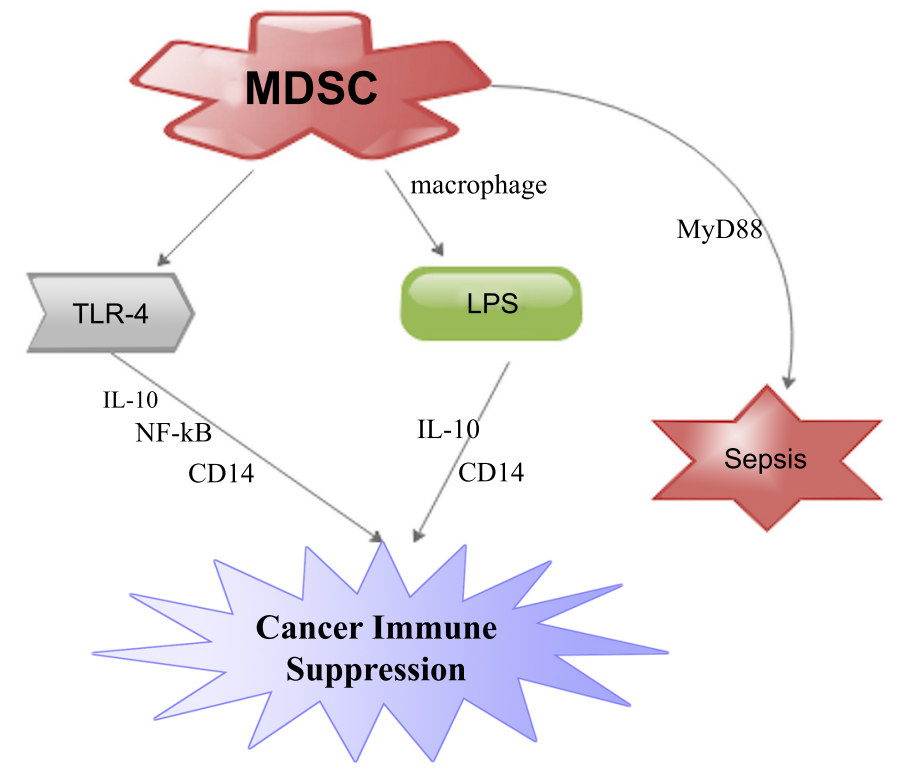

Fig. (1). MDSC contributed to cancer immune suppression via TLR-4 receptor and lipopolysaccharideas (LPS).

Gabrilovich and Nagaraj proposed that inflammation probably amplified CD14 concentrations thereby making MDSC more receptive to LPS and TLR-4 stimulating ligands. They argue that this interaction led to MDSC generation of IL-10 and a significant suppression of immune system [50]. A study has shown that amplification of MDSC subgroups in the spleen is dependent on the TLR adaptor molecule myeloid differentiation primary-response gene 88 (MyD88) [51]. This was evidenced when polymicrobial sepsis triggered by the ligation and perforation of the caecum led to secretion of microbial products into the peritoneum and systemic circulation. Nevertheless, study involving wildtype mice and mice deficient of efficient TLR-4 protein revealed an analogous amplification of MDSC during polymicrobial sepsis (Fig. 1). This means that signaling via TLR-4 may not be prerequisite for MDSC amplification. This further means that MyD88-dependent signaling pathways that might have been activated by other TLRs perhaps participated in the amplification of MDSCs in sepsis [50, 51] (Fig. 1). This also suggests that the triggering of MDSCs is a primary consequence of the host innate immune response to pathogens that secretes TLR ligands. We proposed further studies gear towards the functional roles of TLR and MDSCs in inflammatory cancer microenvironments.

\section{MDSCS, RAGE AND CANCER}

Receptor for advanced glycation end-products (RAGE) is an MHC class III encoded

protein, considered as a damage associated molecular pattern (DAMP) molecule receptor [52]. It functions as the kindred receptor for the archetypal DAMP, HMGB1 as well as numerous S100 proteins such as S100A8 and S100A9 [53]. Several studies have shown that RAGE signaling intermediates in the pathogenesis of epithelial derived cancers. Furthermore, RAGE also triggers fundamental survival pathways like autophagy in cancer cells and promulgating as well as withholding pro-cancer host inflammatory reactions [54, 55].

It has been evidenced that RAGE actively participated in intratumoral MDSC amassment in triggered skin cancer model experiment involving RAGE $^{-/}$mice $[52,56]$. Several studies have also demonstrated that mice defective for the RAGE ligand, S100A9, display a substantial decrease in the rate and encumbrance of colitis-associated colorectal cancers and a demonstration of reductions in intratumoral and splenic MDSC rates [40, 57]. On the other hand, RAGE is not prerequisite for the expansion of MDSCs from myelopoietic progenitor cells or their precise blockade endeavor. This is because MDSCs are located in both RAGE-null and KCR mice phenotypes and therefore are morphologically and functionally stable [40].

Studies have indicated that a larger population of myeloid cells $\left(\mathrm{CD} 11 \mathrm{~b}^{+}\right)$display extreme mature phenotype exhibited by the secretion of mature macrophage marker F4/80 and a deficiency of Gr1 secretion during pancreatic neoplasia deficient in RAGE [40, 58]. It is also known that pro-inflammatory proteins S100A8/A9 triggers MDSCs by interrelating with RAGE and other glycoproteins on the surface of MDSCs and facilitated their migration through NF- 
$\kappa \mathrm{B}$ determined signaling pathway [40, 53] (Fig. 2). Furthermore, RAGE over-secretion inside cancer and stromal sections are simultaneously ligated by S100A8/A9 production by MDSCs which in turn triggers a monitoring chemokine cancer gene silhouette and functions as a positive feed-back loop for the conscription of MDSCs [40, 52] (Fig. 2). Also, DCs and macrophages have proven to express RAGE ligands like HMGB1 in reaction to numerous maturational stimuli. Therefore, HMGB1 expression by MDSCs characterizes an extra machinery for MDSC conscription and so warrants more investigations [59]. We also propose further investigation into the paradoxical roles of RAGE and MDSC in cancers.

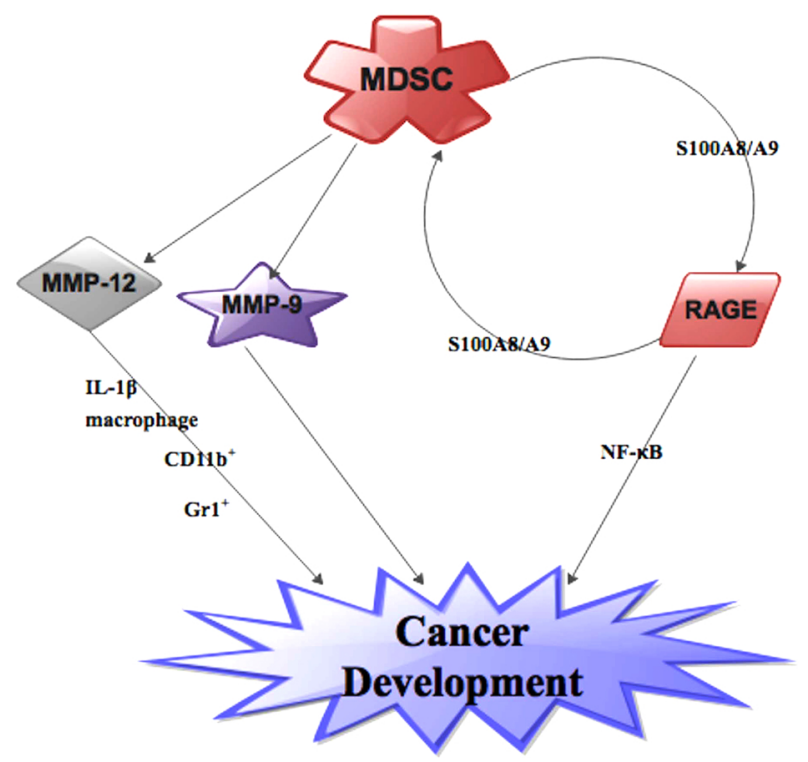

Fig. (2). MDSC contributed to cancer development via MMPs (MMP-9 and MMP1-12) as well as RAGE.

\section{MDSCS, MATRIX METALLOPROTEINASE AND CANCER}

MMPs are an essential group of zinc enzymes conscientious to the mortification of ECM constituents [60, 61]. Several studies have shown that pro-inflammatory factor MMP-12 or macrophage elastase, is secreted principally by macrophages as well as a prerequisite for monocyte conscriptions [62, 63]. It has been demonstrated that extreme secretion of MMP12 in myeloid cells results in anomalous expansion of hematopoietic progenitor cells [64]. Numerous investigators have implicated macrophage-derived MMP-12 in destructive melanoma [65, 66]. Furthermore, MMP-12 polymorphism has also been implicated in breast cancer prognosis [64].

A study has shown that there is upsurge in number MDSCs in MMP-12 $2^{-/}$cancer mice and this upsurge is directly linked to cancer development. The study further showed that macrophage-derived IL-1 $\beta$ stimulated extra MDSCs in bone marrow in these MMP-12/- mice [64]. Another study indicated that mice lacking MMP-12 spawned metastases than their wild-type in Lewis lung pulmonary carcinoma [67]. Li et al. also proposed that MMP12 knockout can augment cancer development by triggering the amassment of MDSCs in the myeloid cells of mice. Their finding supports an earlier report that MMP-12 absence enhanced macrophages-derived IL-1 $\beta$ triggering of myeloid cells into MDSCs (Fig. 2). They therefore concluded that MMP-12 influenced myeloid cells differentiation and IL-1 $\beta$ played a fundamental part in the inter-communication between macrophage and MDSCs in bone marrow milieu in MMP-12 ${ }^{-/}$ mice [64]. Qu et al. demonstrated that the proportion of $\mathrm{CD}_{1} 1 \mathrm{~b}^{+}$and $\mathrm{Gr}-1^{+}$inflammatory cells were appreciably amplified in the lung of 3-month doxycycline-administered bitransgenic mice utilizing a transgenic mouse extreme secretion of MMP-12 model but had conflicting finding in the cancer milieu [68]. Also, Li et al. observe that generation of $\mathrm{CD} 11 \mathrm{~b}^{+} / \mathrm{Gr}^{+}$cells augmented cancer development because these cells were increases in the myeloid cells of MMP-12 knockout mice [64] (Fig. 2).

It is now evidenced that MMP-9 inhibition resulted in a cogent subduing of the immunosuppressive consequence of M-MDSCs than that of G-MDSCs in an in-vitro study. Furthermore, M-MDSCs augmented MMP-9 generation more than G-MDSCs and circulating MMP-9 concentrations is interrelated with early infections as well as consequent 
prognosis [69]. Shao et al. propose that an OPN/MMP- 9 inter-communication is associated with MDSCs production in a lung cancer model. They indicated further that a distinctive OPN- $32 \mathrm{kDa}$ portion was smitten by MMP- 9 which in turn led to modifications in the generation of MDSCs [61]. Initial studies have implicated VEGF as one of the factors that contributes to the secretion of MMP-9 [70, 71]. It is also confirmed that soluble MMP-9 generated by cancer cells stimulates MDSC buildup as well as cancer angiogenesis [71]. Additionally, MMP-9 is able to modify the recruitment of hemopoietic stem cells from the bone marrow niche via the dissolution of the membrane-bound form of c-KitL [72, 73]. Therefore, MMP-9 is a prerequisite in cancer development (Fig. 2). We propose further studies into the roles of other subgroups of MMPs and MDSCs in cancer models.

\section{MDSCS, HIGH MOBILITY GROUP BOX 1 AND CANCER}

High mobility group box 1 (HMGB1), an alarming was initially recognized as a DNA binding protein in the nucleus. It performs various roles such as altering the conformation of DNA to permit the binding of modification proteins, expediting the incorporation of transposons into DNA, as well as steadying nucleosome establishment within the nucleus [74 - 76]. Its responsibility as an expressive protein and an immune chaperone has only been documented a few years ago [74, 77]. HMGB1 also act as a binding protein, stimulator, and/or modulator for many pro-inflammatory molecules [78]. Higher concentrations of HMGB1 have been implicated in various cancers. The upsurge in HMGB1 levels has shown to directly stimulate cancer development [79]. Furthermore, HMGB1 partakes in all fundamental hallmarks of cancer including unlimited proliferation, angiogenesis, invasion and metastasis [80, 81].

Several studies have demonstrated that HMGB1 is vigorously expressed by activated leukocytes or inactively secreted from stressed and necrotic cells $[82,83]$. It is also evidenced that HMGB1 is momentously raised in the circulation of traumatic injury and peaks up within first $6 \mathrm{~h}$ post injury $[84,85]$. Numerous studies have shown that extracellular HMGB1 can attract myeloid derived cells such as PMN-MDSCs, macrophages, DCs and Immature Myeloid Cells(IMC) [59, 86] (Fig. 3). These myeloid derived cells in turn negatively modulate immune reactions in the cancer microenvironment as well as facilitates cancer development [13, 50]. HMGB1 also plays dual roles as Damage Associated Molecular Pattern Molecule (DAMP) and a pro-inflammatory molecule making it a binding protein, stimulator, and/or moderator to many pro-inflammatory molecules that drive MDSC [74, 87]. In-vitro studies revealed that blockage of HMGB1 averted the expansion of MDSCs from bone marrow progenitor cells which means that HMGB1 is prerequisite for the differentiation of MDSCs. Furthermore, In vivo knockout of HMGB1 in cancer-bearing mice decreases MDSC quantities in cancer, spleen, and blood meaning that MGB1 as a chaperone for MDSCs [74].

Several studies have shown that the expression of the protumor cytokines IL-10 and IL-1 $\beta$ is co-chaperone by MDSCs and high HMGB1 levels which means that HMGB1-driven MDSC amassment expedites cancer metastasis [74, 88] (Fig. 3). Numerous studies have also implicated HMGB1 as the trigger of IL-10 drives MDSC amassment as well as $\mathrm{T}$ cell suppressive roles [89 - 91]. It is further proven that a combination of HMGB1 and IL-10 have augmented proinflammatory action as compared to either molecule alone [74, 92]. It is also proven that MDSC-intermediate in the reduction of $\mathrm{T}$ cell L-selectin (CD62L). This mediatory action relied on HMGB1 because HMGB1 amplified MDSC extracellular secretion of A disintegrin and metalloproteinase 17 (ADAM17), a protease that cleaves L-selectin. HMGB1 also augments the pro-inflammatory action of IL-6, TNF- $\alpha$, and prostaglandin E2, three other proinflammatory intermediaries that drive $\operatorname{MDSC}[44,90]$ (Fig. 3).

On the other hand, studies have shown that HMGB1 intermediation with MDSCs could be via RAGE and/or TLR-4 [25] (Fig. 3). Several studies have confirmed that HMGB1 binds mutually to TLR-4 and RAGE, and MDSC secretes these two receptors $[40,49,74]$. Therefore, MDSC contributes significantly to the function of HMGB1 in the cancer milieu. Initially, studies have proven that MDSC generation of IL-10 is modulated by TLR-4 [49]. Furthermore, studies have shown that ethyl pyruvate and glycyrrhizin which are HMGB1 blockers down-regulates MDSC generation of IL-10 during MDSC-macrophage inter-communication [49, 93]. Nevertheless, the differentiation of MDSC from bone marrow progenitor cells as well as ethyl pyruvate reinstated T cell stimulation in the attendance of MDSC. HMGB1 is, therefore, a powerful trigger of MDSC as well as immune suppression while MDSC, macrophages, tumor-infiltrating cells, and tumor cells contribute to the quantity of HMGB1 in the cancer microenvironment [74] (Fig. 3). 


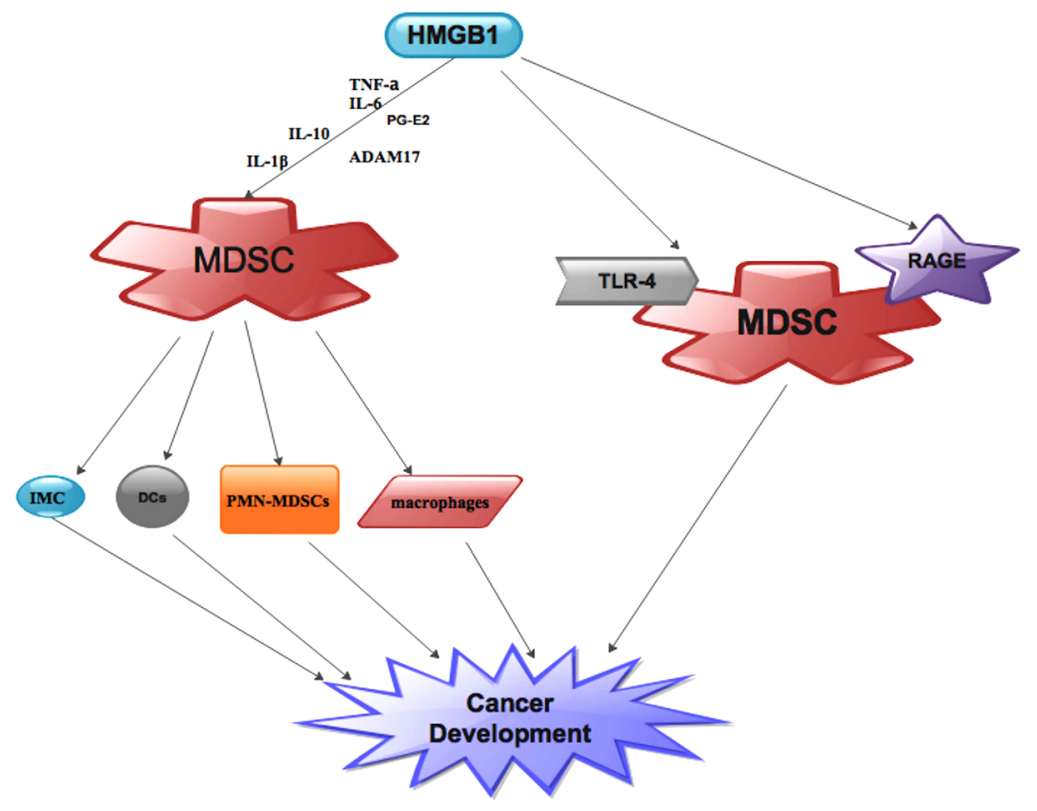

Fig. (3). HMGB1-driven MDSC amassment expedites cancer development and metastasis via PMN-MDSCs, macrophages, DCs and immature myeloid cells (IMC). Further HMGB1 intermediation with MDSCs via RAGE and/or TLR-4 leading to cancer development.

\section{MDSCS IN CANCER MICROENVIRONMENT}

Automatous investigations utilizing cancer or tumor conditioned media (TCM) to cultures of spleen, BM, or isolated myeloid/progenitor cell subsets have revealed mediators and arouses of MDSC function, differentiation, proliferation and survival as well as, T-cell proliferation, DC function and differentiation [24]. Cancers that triggers MDSC proliferation has also demonstrated to release VEGF, GM-CSF, Stem Cell Factor (SCF), FMS-Like Tyrosine kinase 3 ligand (FLT3-L), G-CSF, and/or macrophage-colony stimulating factor (M-CSF) [24]. It evident that using transplantable cancers associated cancer GM-CSF expressed by MDSC increasement via the knock down of GM-CSF in cancer cell lines led to distorted MDSC quantities and subset dissemination resulting in cancer development [24, 94]. In a study that utilizes constant haematopoiesis, GM-CSF and G-CSF not only control proliferation, but also unknowingly mobilization from the BM and spleen [95].

Studies have shown that growth factor injection or release from cancers led to myeloid hyperplasia thus augmenting prosteroid and neutral protease release. The process above resulted in steady mobilization, myeloid progenitor survival, and their dissemination between peripheral and circulating pools [24, 96]. The machineries linked to their mobilization may be analogous to those of haematopoietic progenitor cells because MDSCs comprise of myeloid-committed haematopoietic progenitors and are probably unchanging at the immature differentiation phase [24, 97]. It is now very clear that MDSCs stimulate cancer invasion via the release of MMPs, which partakes in extracellular matrix degradation [24, 98, 99].

Studies have proven that the utilization of a mammary carcinoma deficient in type II Transforming Growth Factor beta (TGF- $\beta$ ) receptor led to an augmented proportion of metastasis and an amplified MDSC infiltrate which confirms the phenomenon above [24, 98]. The augmented invasion above was MMP-dependent; though, it was not certain whether the MMPs were released by MDSCs or by the carcinoma cells in response to MDSC activation [24, 98]. It is postulated that both cell groups are probably involved in MDSCs derived from cancer bearing hosts leading amplified MMP levels as compared to "MDSCs" from non-cancer-bearing hosts [98]. This implies that the amplified invasive capability may be from MDSC-derived MMP expression. Nevertheless, MDSCs likewise appeared at a high incidence in lungs and livers, which are normal metastatic locations [24].

It has been evidenced that even when organ fragments are implanted ectopically, particular organ environment control cancer cell arrest and growth signifying that myeloid cell development and angiogenesis, are crucial, especially hormonal and organ-specific growth factors [24, 100]. Therefore, metastasis is both discriminatory and ineffective, and 
only a limited number of cells survive to form a micrometastasis, a route partly controlled by MDSCs and other myeloid cells [24]. Studies have further demonstrated that splenic MDSCs partake in cancer vasculogenesis via directly differentiating into EPCs [24, 99]. Nevertheless, a subset of circulating progenitor cells is CD11b 170 , and as such, $\mathrm{Gr}^{+} \mathrm{CD} 11 \mathrm{~b}^{+}$cells may be precursors that differentiate and partake in cancer vasculogenesis (BOX 1). The machineries linked to MDSC suppression of T-cell roles depends largely on NOS2176, ROS, ARG1177, cyclooxygenase 2 (COX2), and hypothetically upregulation of IL-10 as prime machineries [24].

It is now clear that the adoptive transfer of MDSCs suggestively stimulated cancer growth in animal models, and Gr1+ cell depletion in cancer-bearing mice blocks cancer development, lessens metastasis, and lengthens survival [24, 101]. Studies have demonstrated that some chemotherapeutic agents like gemcitabine, 5-fluorouracil, and docetaxel differently suppress MDSCs [24, 102]. Numerous studies of cancer-bearing mice, and a few clinical reports utilizing medicines that target MDSCs or their function, have proven that in mice MDSC diminution slowdown cancer initiation, progression, and lengthen ssurvival [24, 103].

\section{MDSCS AND CANCER METASTASIS}

Cancers usually invade the neighboring tissue, travers into the circulation, seed and proliferate in a distant tolerant niche before there are able to metastasize [104]. It is becoming clearer that MDSC actively partakes in cancer metastasis at all phases. It is evidenced that MDSC stimulates malignancy or metastasis by stimulating stemness of cancer cells or by increasing the cancer stem cell groupings [104]. Studies have shown that MDSCs directly triggered malignant cell proliferation and overpowered immune elimination of malignant metastasis in allogeneic mice via alteration of the mTOR pathway, which offers an automatous foundation for steering MDSCs to decrease the possibilities of tumor malignancy [105, 106]. Wang et al. evidenced that cancer metastasis and Gr-11 CD11b1 MDSCs at postoperative period were augmented in quantity to the severity of surgery stress. They demonstrated this with tentative lung metastasis mice models [107].

Another study revealed that circulating CD14 HLA-DRlow M-MDSC were concurrent with extra-thoracic metastases in non-small cell lung cancer (NSCLC) patients [108]. Furthermore, the upsurge in IDO-secretion CD45 $\mathrm{CD} 33^{+} \mathrm{CD} 14^{-} \mathrm{CD} 15^{-}$MDSC in breast cancer tissue was also simultaneous with augmented lymph node metastasis in patients with breast cancer [104, 109]. Nevertheless, the evolution of metastases and poor survival was interrelated with an upsurge in both circulating $\mathrm{CD} 11 \mathrm{~b}^{+} \mathrm{CD} 14^{-} \mathrm{CD} 15^{+} \mathrm{PMN}-\mathrm{MDSC}$ as well as M-MDSC in melanoma individuals [110, 111].

Several studies have shown that pro-inflammatory proteins S100A8 and S100A9 are effective chemoattractants for MDSC. These two factors have recently been incriminated in the advancement of cancer growth and metastases via MDSC axis [40, 57]. It is also evidenced that S100A8/A9 could directly trigger serum amyloid A (SAA) 3 which in turn magnetizes MDSC to pre-metastatic lungs via NF- $\kappa \mathrm{B}$ signaling pathway in a TLR4-dependent manner thereby accelerating metastasis [104, 112]. Therefore, MDSC conscription to cancer locations may symbolize a rancorous circle. MDSC primarily conscripted to cancer location via cancer-derived chemokines may likewise expedite the conscription of other MDSC through S100A8/A9 proteins [57].

A study revealed that amassment of PMN-MDSC is interrelated with augmented bone metastasis in 4T1 model of breast cancer [98]. Also, the administration of MDSC as well as 4T1 cells together resulted in augmented lung metastasis. This study also revealed that MDSC in 4T1 cancers augmented the secretion of numerous MMPs which were very imperative in intermediating invasiveness of 4T1 cells in vitro and in vivo [98]. It is further evidence that MDSC decreases protease inhibitors like neutrophilic granule protein, a blocker of cancer intrusiveness and metastasis [113]. Nevertheless, in mammary carcinoma cells, deletion of TGF- $\beta$ receptor II (Tgfbr2) led to an upsurge in MDSC insinuation into cancers intermediated via SDF-1 as well as CXCL5. Also, in SMAD4-deficient mice colon carcinoma, blockade of TGF- $\beta$ signaling triggered MDSC conscription as well as cancer invasion via CCL9 dependent pathway $[104,114]$.

Furthermore, the meticulous deletion of Tgfbr2 in myeloid cells expressively subdued cancer metastasis. Moreover, Tgfbr2 deficiency in myeloid cells diminished arg-1 action as well as NO generation which in turn facilitated IFN- $\gamma$ generation as well as an enhanced systemic immunity [104, 115]. Nevertheless, HIF-1 $\alpha$-dependent kit ligand secreted by hypoxic cancer cells in a mouse mammary cancer model activated c-Kit ${ }^{+} \mathrm{CD} 11 \mathrm{~b}^{+}$Ly6Ghigh PMN-MDSC at the principal cancer site as well as facilitated metastasis [116]. It is further shown that M-MDSC directly triggered expansion of aldehyde dehydrogenase $-1^{+}$(ALDH1) pancreatic cancer stem cells in mice models of pancreatic cancer as 
we as human CD14 ${ }^{+}$HLA-DR $^{-}$M-MDSC $[117,118]$.

Moreover, the buildup of $\operatorname{Lin}^{-} \mathrm{CD} 45^{+} \mathrm{CD} 33^{+} \mathrm{MDSC}$ is interconnected to poor life expectancy in metastatic and nonmetastatic ovarian cancer patients. Also, MDSC directly interrelated with ovarian cancer cells and triggered their stemness. Additionally, at principal cancer and metastatic locations, MDSC generate IL-6 which in turn bestows invasive abilities of breast cancer cells as well as triggers distant metastases via tenacious stimulation of STAT3 in cancer cells [104].

\section{MDSCS AND CANCER ANGIOGENESIS}

Angiogenesis, the sprouting of new blood vessels, happens at distinctive phases during embryonic formation, physiological activities like wound healing and reproduction. Angiogenesis also occurs in several diseases condition such as inflammation, cancer development, and metastasis [119, 120]. An earlier study indicated that neovascularization appears around cancers. In this study it was postulated that the sprouting of new blood vessel is a prerequisite source of nutrients and oxygen to cancer cells during exponential cancer growth [121]. A current study has shown that new blood vessels arise from antecedent vessels via stimulation, proliferation and migration of endothelial cells [122]. It is now clear that Vascular Endothelial Growth Factor (VEGF) and basic fibroblast growth factor (bFGF) trigger the proliferation and migration of innately inactive endothelial cells leading to the development of new vessel structures during embryonic formation and cancer development [119, 123]. Vasculogenesis is the amalgamation of new blood vessels from specific endothelial cells or progenitor cells. Initially, vasculogenesis was assumed to be limited to the development of the preliminary vascular tree during embryonic vascular formation [119].

Kujawski et al. were among the first researchers to demonstrate that MDSCs might actively partake in cancer angiogenesis. They indicated that MDSCs actively triggers STAT3, which in turn increases the secretion of numerous angiogenic genes [124]. It is now obvious that VEGF a pro-inflammatory growth factor triggers angiogenesis during tumorigenesis. It is also now clear that VEGF contributes significantly to poor cancer prognosis. Therefore, tumors that generate extreme levels of VEGF will usually have a poorer prognosis. A study showed that VEGF blocks nuclear factor kappa light-chain-enhancer (NF- $\kappa \mathrm{B})$ stimulation which in turn inhibits DC advancements although concurrently, they facilities MDSC buildup [125]. It has been demonstrated that MDSCs secretes VEGF receptor empowering VEGF to serve as a chemoattractant for MDSCs. Nevertheless, Kusmartsev et al demonstrated that ROS generated by MDSCs amplifies oxidative stress which in turn increases MDSC secretion of VEGF receptors [126]. In solid tumors, however, so many factors actively partake in oxidative stress. The most influential among this factor is cancer microenvironment because it determines the responsiveness of MDSCs to VEGF. Kujawski et al. further explained that during tumorigenesis besides tumor cells, MDSCs themselves generate VEGF which in turn triggers an autocrine feedback loop that maintains MDSC amassments [124].

Mucha et al. demonstrated that cancer cells administered with IL-28 before and during their experiment for $6 \mathrm{~h}$ triggered 3D vessel sprouting by endothelial cells [127]. An earlier study had indicated that IL-28-mediated amplification of VEGF-C and IL-18 secretion in cancer cells [128].

Mucha et al further indicated combined culturing of HUVECs with control tumor cells or with IL-28 alone for $6 \mathrm{~h}$ triggered little endothelial cell bifurcations. They concluded that prolonged stimulation may trigger IL-28 cancer cells to secretion of angiogenic factors resulting in angiogenesis [127]. Therefore, MDSCs release IL-28 which in turn triggered cancer angiogenesis predominantly via an upsurge in expressing angiogenic proteins in cancer cells [127]. Studies have shown that MDSCs facilities cancer angiogenesis by generating angiogenic factors as well as matrix degrading enzymes like VEGF and MMP-9 [129, 130].

A Study has further indicated that unceasing upsurge of VEGF in the peripheral blood leads to an upsurge in the generation of immature Gr-11 myeloid cells. Furthermore, sustained extreme concentration VEGF resulted in substantial blockade of DC formation [131]. Moreover, researches demonstrated that the upsurge of VEGF is linked to the blockade of the movement of transcription factor NF- $\kappa B$ in bone marrow progenitor cells [107, 125]. Studies have also shown that management of patients with metastatic renal cell cancer with a VEGF specific inhibiting antibody avastin led to a reduction in the size of CD11b1 VEGFR11 subgroups of MDSCs in peripheral blood [107, 126]. Nevertheless, blockade of the responsibilities of MMP-9 in cancer-bearing mice reduced the quantity of MDSCs in cancer mass and spleen as well as led to a substantial deferment in the growth of extemporaneous NeuT cancers [72]. Wang et al also demonstrated that surgery-triggered CD11b1 CD331 HLA-DR- MDSCs vigorously accelerated to cancer angiogenesis as well as facilitated the generation MMP-9 and VEGF [107]. 


\section{THERAPEUTIC POTENTIALS OF MDSCS IN CANCER}

Studies have shown that MDSC provides double discrete beneficial curative potentials. In cancer individuals, particularly in those taking immunotherapies, the outcomes of MDSC are normally disadvantageous therefore intermediation should be angled at diminishing the consequences of MDSC [12]. This can be accomplished via terminating their activities, via lethal stimulating myeloid differentiation, via blocking or diminishing MDSC growth, or via blocking their function [12]. Studies have shown that MDSC differentiation to macrophages or DCs can be attained via clinically accepted medications such as vitamin D3 or derivatives, and vitamin A or derivatives like AllTransretinoic Acid (ATRA). It is clear that the use of ATRA enriches the anti-cancer outcomes of cancer vaccines in cancer-bearing mice $[12,132]$. Also, it decreases the buildup of MDSC and enhances antigen-specific immune responses in patients with renal-cell carcinoma [12].

Furthermore, inhibiting pathways that contribute to MDSC development, such as those of VEGF and SCF, may also decrease MDSC buildup. Studies have proven that sunitinib a clinically accepted tyrosine kinase inhibitor that blocks ckit, VEGFR, PDGFR, Flt3, CSF-1 and RET pathways, decreases MDSC buildup and prohibited T- cell activation and Treg expansion in cancer bearing mice, and it was linked to a diminution in the quantity of MDSC and a reversal of $\mathrm{CD} 4{ }^{+} \mathrm{CD} 25^{\mathrm{hi}} \mathrm{Foxp}^{+}$Treg cell elevation in patients with renal cell carcinoma [12, 133, 134]. Also, inhibition of PGE2 generation by COX-2 inhibitors decreased the development of MDSC and blocked cancer growth in cancer-bearing mice [12].

It is also now clear that MDSC can be destroyed with radiotherapy, monoclonal antibodies targeting myeloid markers or chemotherapeutic medications. Gemcitabine or 5-fluorouracil has proven to effect in destroying MDSC while conserving the quantities of $\mathrm{T}$ or NK cells, which improves anticancer immune responses in cancer-bearing mice $[12,103,135]$. Studies have shown that blockade of enzymes such as nitro-aspirines (NO-aspirines) and phosphodiesterase 5 inhibitors led to cancer reduction. NO-aspirin inhibited both iNOS and arginase actions in cancerassociated MDSC. It is evidenced that aspirin blocked arginase, while iNOS was blocked by the NO expressed by the medication $[12,136]$. It is also clear that NO-aspirin also has antioxidant action and has proven to decrease the indigenous generation of peroxynitrites, known mediators of the immune suppressive consequence. Nevertheless, blockade of the generation of PGE2 by celecoxib, a non-steroidal anti-inflammatory medication that inhibits cyclooxygenase 2 (COX-2) action, prohibited chemical stimulation of huge abdominal cancers as well as a decrease in arginase-1 and iNOS secretion and the number of MDSC in the spleen of cancer bearing mice, together with a reinstatement of $\mathrm{CD}^{+}$cell quantities and functionality $[12,137]$.

\section{CONCLUSION}

MDSC contributed to cancer immune suppression via a TLR-4 receptor and Lipopolysaccharideas (LPS). Furthermore, MDSC contributed to cancer development via MMPs (MMP-9 and MMP1-12) as well as RAGE. In the cancer microenvironment, HMGB1-driven MDSC amassment expedites cancer development and metastasis via PMNMDSCs, macrophages, DCs and Immature Myeloid Cells (IMC). Further HMGB1 intermediation with MDSCs via RAGE and/or TLR-4 leads to cancer development. Also, MDSCs have already proven potent in some cancers and are currently been used as treatment options although further studies are needed in some other cancers.

\section{CONSENT FOR PUBLICATION}

Not applicable.

\section{CONFLICT OF INTEREST}

The author declares no conflict of interest, financial or otherwise.

\section{ACKNOWLEDGMENTS}

Declared none.

\section{REFERENCES}

[1] Casacuberta-Serra S, Parés M, Golbano A, Coves E, Espejo C, Barquinero J. Myeloid-derived suppressor cells can be efficiently generated from human hematopoietic progenitors and peripheral blood monocytes. Immunol Cell Biol 2017; 95(6): 538-48. [http://dx.doi.org/10.1038/icb.2017.4] [PMID: 28108746] 
[2] Gabrilovich DI, Nagaraj S. Myeloid-derived suppressor cells as regulators of the immune system. Nat Rev Immunol 2009; 9(3): 162-74. [http://dx.doi.org/10.1038/nri2506] [PMID: 19197294]

[3] Wei W-C, Lin S-Y, Lan C-W, et al. Inhibiting MDSC differentiation from bone marrow with phytochemical polyacetylenes drastically impairs tumor metastasis. Sci Rep 2016; 6: 36663.

[http://dx.doi.org/10.1038/srep36663] [PMID: 27857157]

[4] Condamine T, Gabrilovich DI. Molecular mechanisms regulating myeloid-derived suppressor cell differentiation and function. Trends Immunol 2011; 32(1): 19-25. [http://dx.doi.org/10.1016/j.it.2010.10.002] [PMID: 21067974]

[5] Lechner MG, Liebertz DJ, Epstein AL. Characterization of cytokine-induced myeloid-derived suppressor cells from normal human peripheral blood mononuclear cells. J Immunol 2010; 185(4): 2273-84.

[http://dx.doi.org/10.4049/jimmunol.1000901] [PMID: 20644162]

[6] Kowanetz M, Wu X, Lee J, et al. Granulocyte-colony stimulating factor promotes lung metastasis through mobilization of Ly6G+Ly6C+ granulocytes. Proc Natl Acad Sci USA 2010; 107(50): 21248-55. [http://dx.doi.org/10.1073/pnas.1015855107] [PMID: 21081700]

[7] Serafini P. Myeloid derived suppressor cells in physiological and pathological conditions: The good, the bad, and the ugly. Immunol Res 2013; 57(1-3): 172-84. [http://dx.doi.org/10.1007/s12026-013-8455-2] [PMID: 24203443]

[8] Martin F, Apetoh L, Ghiringhelli F. Role of myeloid-derived suppressor cells in tumor immunotherapy. Immunotherapy 2012; 4(1): 43-57. [http://dx.doi.org/10.2217/imt.11.154] [PMID: 22150000]

[9] Sica A, Bronte V. Altered macrophage differentiation and immune dysfunction in tumor development. J Clin Invest 2007; $117(5)$ : 1155-66. [http://dx.doi.org/10.1172/JCI31422] [PMID: 17476345]

[10] Freeman GJ, Long AJ, Iwai Y, et al. Engagement of the PD-1 immunoinhibitory receptor by a novel B7 family member leads to negative regulation of lymphocyte activation. J Exp Med 2000; 192(7): 1027-34. [http://dx.doi.org/10.1084/jem.192.7.1027] [PMID: 11015443]

[11] Chikamatsu K, Sakakura K, Toyoda M, Takahashi K, Yamamoto T, Masuyama K. Immunosuppressive activity of CD14+ HLA-DR- cells in squamous cell carcinoma of the head and neck. Cancer Sci 2012; 103(6): 976-83. [http://dx.doi.org/10.1111/j.1349-7006.2012.02248.x] [PMID: 22360618]

[12] Gimeno R, Barquinero J. Myeloid-Derived Suppressor Cells (MDSC): Another player in the orchestra. Inmunologia 2011; 30(2): 45-53. [http://dx.doi.org/10.1016/S0213-9626(11)70015-4]

[13] Youn JI, Gabrilovich DI. The biology of myeloid-derived suppressor cells: The blessing and the curse of morphological and functional heterogeneity. Eur J Immunol 2010; 40(11): 2969-75. [http://dx.doi.org/10.1002/eji.201040895] [PMID: 21061430]

[14] Bronte V, Wang M, Overwijk WW, et al. Apoptotic death of CD8+ T lymphocytes after immunization: Induction of a suppressive population of Mac-1+/Gr-1+ cells. J Immunol 1998; 161(10): 5313-20. [PMID: 9820504]

[15] Schmielau J, Finn OJ. Activated granulocytes and granulocyte-derived hydrogen peroxide are the underlying mechanism of suppression of Tcell function in advanced cancer patients. Cancer Res 2001; 61(12): 4756-60. [PMID: 11406548]

[16] Youn J-I, Nagaraj S, Collazo M, Gabrilovich DI. Subsets of myeloid-derived suppressor cells in tumor-bearing mice. J Immunol 2008; 181(8): 5791-802. [http://dx.doi.org/10.4049/jimmunol.181.8.5791] [PMID: 18832739]

[17] Fleming TJ, Fleming ML, Malek TR. Selective expression of Ly-6G on myeloid lineage cells in mouse bone marrow. RB6-8C5 mAb to granulocyte-differentiation antigen (Gr-1) detects members of the Ly-6 family. J Immunol 1993; 151(5): 2399-408. [PMID: 8360469]

[18] Ribechini E, Leenen PJ, Lutz MB. Gr-1 antibody induces STAT signaling, macrophage marker expression and abrogation of myeloid-derived suppressor cell activity in BM cells. Eur J Immunol 2009; 39(12): 3538-51. [http://dx.doi.org/10.1002/eji.200939530] [PMID: 19830733]

[19] Rodriguez PC, Ernstoff MS, Hernandez C, et al. Arginase I-producing myeloid-derived suppressor cells in renal cell carcinoma are a subpopulation of activated granulocytes. Cancer Res 2009; 69(4): 1553-60. [http://dx.doi.org/10.1158/0008-5472.CAN-08-1921] [PMID: 19201693]

[20] Peranzoni E, Zilio S, Marigo I, et al. Myeloid-derived suppressor cell heterogeneity and subset definition. Curr Opin Immunol 2010; 22(2): 238-44. [http://dx.doi.org/10.1016/j.coi.2010.01.021] [PMID: 20171075]

[21] Nikolic T, de Bruijn MF, Lutz MB, Leenen PJ. Developmental stages of myeloid dendritic cells in mouse bone marrow. Int Immunol 2003; 15(4): 515-24.

[http://dx.doi.org/10.1093/intimm/dxg050] [PMID: 12663681] 
[22] Nakano H, Yanagita M, Gunn MD. CD11c(+)B220(+)Gr-1(+) cells in mouse lymph nodes and spleen display characteristics of plasmacytoid dendritic cells. J Exp Med 2001; 194(8): 1171-8. [http://dx.doi.org/10.1084/jem.194.8.1171] [PMID: 11602645]

[23] Gurbaxani B, Dela Cruz LL, Chintalacharuvu K, Morrison SL. Analysis of a family of antibodies with different half-lives in mice fails to find a correlation between affinity for FcRn and serum half-life. Mol Immunol 2006; 43(9): 1462-73. [http://dx.doi.org/10.1016/j.molimm.2005.07.032] [PMID: 16139891]

[24] Talmadge JE, Gabrilovich DI. History of myeloid-derived suppressor cells. Nat Rev Cancer 2013; 13(10): 739-52. [http://dx.doi.org/10.1038/nrc3581] [PMID: 24060865]

[25] Ostrand-Rosenberg S, Sinha P, Beury DW, Clements VK. Cross-talk between Myeloid-Derived Suppressor Cells (MDSC), macrophages, and dendritic cells enhances tumor-induced immune suppression. Semin Cancer Biol 2012; 22(4): $275-81$. [http://dx.doi.org/10.1016/j.semcancer.2012.01.011]

[26] Bronte V, Brandau S, Chen S-H, et al. Recommendations for myeloid-derived suppressor cell nomenclature and characterization standards. Nat Commun 2016; 7: 12150 . [http://dx.doi.org/10.1038/ncomms12150] [PMID: 27381735]

[27] Lin EY, Li J-F, Gnatovskiy L, et al. Macrophages regulate the angiogenic switch in a mouse model of breast cancer. Cancer Res 2006; 66(23): 11238-46. [http://dx.doi.org/10.1158/0008-5472.CAN-06-1278] [PMID: 17114237]

[28] Zheng Y, Cai Z, Wang S, et al. Macrophages are an abundant component of myeloma microenvironment and protect myeloma cells from chemotherapy drug-induced apoptosis. Blood 2009; 114(17): 3625-8. [http://dx.doi.org/10.1182/blood-2009-05-220285] [PMID: 19710503]

[29] Mantovani A, Sica A, Allavena P, Garlanda C, Locati M. Tumor-associated macrophages and the related myeloid-derived suppressor cells as a paradigm of the diversity of macrophage activation. Hum Immunol 2009; 70(5): 325-30 [http://dx.doi.org/10.1016/j.humimm.2009.02.008] [PMID: 19236898]

[30] Sinha P, Clements VK, Bunt SK, Albelda SM, Ostrand-Rosenberg S. Cross-talk between myeloid-derived suppressor cells and macrophages subverts tumor immunity toward a type 2 response. J Immunol 2007; 179(2): 977-83. [http://dx.doi.org/10.4049/jimmunol.179.2.977] [PMID: 17617589]

[31] Mazzoni A, Bronte V, Visintin A, et al. Myeloid suppressor lines inhibit T cell responses by an NO-dependent mechanism. J Immunol 2002; 168(2): 689-95.

[http://dx.doi.org/10.4049/jimmunol.168.2.689] [PMID: 11777962]

[32] Kusmartsev S, Nefedova Y, Yoder D, Gabrilovich DI. Antigen-specific inhibition of CD8+ T cell response by immature myeloid cells in cancer is mediated by reactive oxygen species. J Immunol 2004; 172(2): 989-99. [http://dx.doi.org/10.4049/jimmunol.172.2.989] [PMID: 14707072]

[33] Sinha P, Clements VK, Ostrand-Rosenberg S. Reduction of myeloid-derived suppressor cells and induction of M1 macrophages facilitate the rejection of established metastatic disease. J Immunol 2005; 174(2): 636-45. [http://dx.doi.org/10.4049/jimmunol.174.2.636] [PMID: 15634881]

[34] Cao S, Liu J, Chesi M, et al. Differential regulation of IL-12 and IL-10 gene expression in macrophages by the basic leucine zipper transcription factor c-Maf fibrosarcoma. J Immunol 2002; 169(10): 5715-25. [http://dx.doi.org/10.4049/jimmunol.169.10.5715] [PMID: 12421951]

[35] DeNardo DG, Barreto JB, Andreu P, et al. CD4(+) T cells regulate pulmonary metastasis of mammary carcinomas by enhancing protumor properties of macrophages. Cancer Cell 2009; 16(2): 91-102. [http://dx.doi.org/10.1016/j.ccr.2009.06.018] [PMID: 19647220]

[36] Murai M, Turovskaya $\mathrm{O}$, Kim G, et al. Interleukin 10 acts on regulatory $\mathrm{T}$ cells to maintain expression of the transcription factor Foxp3 and suppressive function in mice with colitis. Nat Immunol 2009; 10(11): 1178-84. [http://dx.doi.org/10.1038/ni.1791] [PMID: 19783988]

[37] Huntington ND, Vosshenrich CA, Di Santo JP. Developmental pathways that generate natural-killer-cell diversity in mice and humans. Nat Rev Immunol 2007; 7(9): 703-14. [http://dx.doi.org/10.1038/nri2154] [PMID: 17717540]

[38] Balkwill F, Charles KA, Mantovani A. Smoldering and polarized inflammation in the initiation and promotion of malignant disease. Cancer Cell 2005; 7(3): 211-7. [http://dx.doi.org/10.1016/j.ccr.2005.02.013] [PMID: 15766659]

[39] Ostrand-Rosenberg S, Sinha P. Myeloid-derived suppressor cells: Linking inflammation and cancer. J Immunol 2009; 182(8): 4499-506. [http://dx.doi.org/10.4049/jimmunol.0802740] [PMID: 19342621]

[40] Sinha P, Okoro C, Foell D, Freeze HH, Ostrand-Rosenberg S, Srikrishna G. Proinflammatory S100 proteins regulate the accumulation of myeloid-derived suppressor cells. J Immunol 2008; 181(7): 4666-75. [http://dx.doi.org/10.4049/jimmunol.181.7.4666] [PMID: 18802069]

[41] Fridlender ZG, Sun J, Kim S, et al. Polarization of tumor-associated neutrophil phenotype by TGF- $\beta$ : "N1" versus "N2" TAN. Cancer Cell 2009; 16(3): 183-94. 
[http://dx.doi.org/10.1016/j.ccr.2009.06.017] [PMID: 19732719]

[42] Mishalian I, Granot Z, Fridlender ZG. The diversity of circulating neutrophils in cancer. Immunobiology 2017; 222(1): 82-8. [http://dx.doi.org/10.1016/j.imbio.2016.02.001] [PMID: 26874580]

[43] Movahedi K, Laoui D, Gysemans C, et al. Different tumor microenvironments contain functionally distinct subsets of macrophages derived from Ly6C(high) monocytes. Cancer Res 2010; 70(14): 5728-39. [http://dx.doi.org/10.1158/0008-5472.CAN-09-4672] [PMID: 20570887]

[44] Sinha P, Clements VK, Fulton AM, Ostrand-Rosenberg S. Prostaglandin E2 promotes tumor progression by inducing myeloid-derived suppressor cells. Cancer Res 2007; 67(9): 4507-13.

[http://dx.doi.org/10.1158/0008-5472.CAN-06-4174] [PMID: 17483367]

[45] Hu C-E, Gan J, Zhang R-D, Cheng Y-R, Huang G-J. Up-regulated myeloid-derived suppressor cell contributes to hepatocellular carcinoma development by impairing dendritic cell function. Scand J Gastroenterol 2011; 46(2): 156-64. [http://dx.doi.org/10.3109/00365521.2010.516450] [PMID: 20822377]

[46] Poschke I, Mao Y, Adamson L, Salazar-Onfray F, Masucci G, Kiessling R. Myeloid-derived suppressor cells impair the quality of dendritic cell vaccines. Cancer Immunol Immunother 2012; 61(6): 827-38. [http://dx.doi.org/10.1007/s00262-011-1143-y] [PMID: 22080405]

[47] McKenzie BS, Kastelein RA, Cua DJ. Understanding the IL-23-IL-17 immune pathway. Trends Immunol 2006; 27(1): 17-23. [http://dx.doi.org/10.1016/j.it.2005.10.003] [PMID: 16290228]

[48] Jiang Q, Akashi S, Miyake K, Petty HR. Lipopolysaccharide induces physical proximity between CD14 and toll-like receptor 4 (TLR4) prior to nuclear translocation of NF- $\kappa$ B. J Immunol 2000; 165(7): 3541-4. [http://dx.doi.org/10.4049/jimmunol.165.7.3541] [PMID: 11034352]

[49] Bunt SK, Clements VK, Hanson EM, Sinha P, Ostrand-Rosenberg S. Inflammation enhances myeloid-derived suppressor cell cross-talk by signaling through Toll-like receptor 4. J Leukoc Biol 2009; 85(6): 996-1004. [http://dx.doi.org/10.1189/jlb.0708446] [PMID: 19261929]

[50] Gabrilovich DI, Nagaraj S. Myeloid-derived suppressor cells as regulators of the immune system. Nat Rev Immunol 2009; 9(3): 162-74. [http://dx.doi.org/10.1038/nri2506] [PMID: 19197294]

[51] Delano MJ, Scumpia PO, Weinstein JS, et al. MyD88-dependent expansion of an immature GR-1(+)CD11b(+) population induces T cell suppression and Th2 polarization in sepsis. J Exp Med 2007; 204(6): 1463-74. [http://dx.doi.org/10.1084/jem.20062602] [PMID: 17548519]

[52] Vernon PJ, Loux TJ, Schapiro NE, et al. The receptor for advanced glycation end products promotes pancreatic carcinogenesis and accumulation of myeloid-derived suppressor cells. J Immunol 2013; 190(3): 1372-9. [http://dx.doi.org/10.4049/jimmunol.1201151] [PMID: 23269246]

[53] Turovskaya O, Foell D, Sinha P, et al. RAGE, carboxylated glycans and S100A8/A9 play essential roles in colitis-associated carcinogenesis. Carcinogenesis 2008; 29(10): 2035-43. [http://dx.doi.org/10.1093/carcin/bgn188] [PMID: 18689872]

[54] Kang R, Tang D, Schapiro NE, et al. The Receptor for Advanced Glycation End products (RAGE) sustains autophagy and limits apoptosis, promoting pancreatic tumor cell survival. Cell Death Differ 2010; 17(4): 666-76. [http://dx.doi.org/10.1038/cdd.2009.149] [PMID: 19834494]

[55] Kang R, Loux T, Tang D, et al. The expression of the Receptor for Advanced Glycation Endproducts (RAGE) is permissive for early pancreatic neoplasia. Proc Natl Acad Sci USA 2012; 109(18): 7031-6. [http://dx.doi.org/10.1073/pnas.1113865109] [PMID: 22509024]

[56] Gebhardt C, Riehl A, Durchdewald M, et al. RAGE signaling sustains inflammation and promotes tumor development. J Exp Med 2008; 205(2): 275-85. [http://dx.doi.org/10.1084/jem.20070679] [PMID: 18208974]

[57] Ichikawa M, Williams R, Wang L, Vogl T, Srikrishna G. S100A8/A9 activate key genes and pathways in colon tumor progression. Mol Cancer Res 2011; 9(2): 133-48. [http://dx.doi.org/10.1158/1541-7786.MCR-10-0394] [PMID: 21228116]

[58] Leenen PJ, de Bruijn MF, Voerman JS, Campbell PA, van Ewijk W. Markers of mouse macrophage development detected by monoclonal antibodies. J Immunol Methods 1994; 174(1-2): 5-19.

[http://dx.doi.org/10.1016/0022-1759(94)90005-1] [PMID: 8083537]

[59] Campana L, Bosurgi L, Bianchi ME, Manfredi AA, Rovere-Querini P. Requirement of HMGB1 for stromal cell-derived factor-1/CXCL12dependent migration of macrophages and dendritic cells. J Leukoc Biol 2009; 86(3): 609-15. [http://dx.doi.org/10.1189/jlb.0908576] [PMID: 19414537]

[60] Turpeenniemi-Hujanen T. Gelatinases (MMP-2 and -9) and their natural inhibitors as prognostic indicators in solid cancers. Biochimie 2005; 87(3-4): 287-97. [http://dx.doi.org/10.1016/j.biochi.2005.01.014] [PMID: 15781315]

[61] Shao L, Zhang B, Wang L, Wu L, Kan Q, Fan K. MMP-9-cleaved osteopontin isoform mediates tumor immune escape by inducing expansion of myeloid-derived suppressor cells. Biochem Biophys Res Commun 2017; 493(4): 1478-84. 
[http://dx.doi.org/10.1016/j.bbrc.2017.10.009] [PMID: 28986261]

[62] Rodríguez-Pla A, Martínez-Murillo F, Savino PJ, Eagle RC Jr, Seo P, Soloski MJ. MMP-12, a novel matrix metalloproteinase associated with giant cell arteritis. Rheumatology (Oxford) 2009; 48(11): 1460-1. [http://dx.doi.org/10.1093/rheumatology/kep271] [PMID: 19736181]

[63] Hautamaki RD, Kobayashi DK, Senior RM, Shapiro SD. Requirement for macrophage elastase for cigarette smoke-induced emphysema in mice. Science 1997 ; 277(5334): 2002-4. [http://dx.doi.org/10.1126/science.277.5334.2002] [PMID: 9302297]

[64] Li J, Zhang X, Liu Q, et al. Myeloid-derived suppressor cells accumulate among myeloid cells contributing to tumor growth in matrix metalloproteinase12 knockout mice. Cell Immunol 2017.

[65] Zhang Z, Zhu S, Yang Y, Ma X, Guo S. Matrix metalloproteinase-12 expression is increased in cutaneous melanoma and associated with tumor aggressiveness. Tumour Biol 2015; 36(11): 8593-600. [http://dx.doi.org/10.1007/s13277-015-3622-9] [PMID: 26040769]

[66] Shin A, Cai Q, Shu X-O, Gao Y-T, Zheng W. Genetic polymorphisms in the matrix metalloproteinase 12 gene (MMP12) and breast cancer risk and survival: The shanghai breast cancer study. Breast Cancer Res 2005; 7(4): R506-12. [http://dx.doi.org/10.1186/bcr1033] [PMID: 15987457]

[67] Houghton AM, Grisolano JL, Baumann ML, et al. Macrophage elastase (matrix metalloproteinase-12) suppresses growth of lung metastases. Cancer Res 2006; 66(12): 6149-55. [http://dx.doi.org/10.1158/0008-5472.CAN-04-0297] [PMID: 16778188]

[68] Qu P, Yan C, Du H. Matrix metalloproteinase 12 overexpression in myeloid lineage cells plays a key role in modulating myelopoiesis, immune suppression, and lung tumorigenesis. Blood 2011; 117(17): 4476-89. [http://dx.doi.org/10.1182/blood-2010-07-298380] [PMID: 21378275]

[69] Lee S-E, Lim J-Y, Kim TW, et al. Matrix metalloproteinase-9 in monocytic myeloid-derived suppressor cells correlate with early infections and clinical outcomes in allogeneic hematopoietic stem cell transplantation. Biol Blood Marrow Transplant 2018; 24(1): 32-42. [http://dx.doi.org/10.1016/j.bbmt.2017.08.017] [PMID: 28844945]

[70] Bergers G, Brekken R, McMahon G, et al. Matrix metalloproteinase-9 triggers the angiogenic switch during carcinogenesis. Nat Cell Biol 2000; 2(10): 737-44. [http://dx.doi.org/10.1038/35036374] [PMID: 11025665]

[71] Parker KH, Beury DW, Ostrand-Rosenberg S. Myeloid-derived suppressor cells: Critical cells driving immune suppression in the tumor microenvironment Ed Eds Advances in cancer research Elsevier; pp 95-139 1995.

[72] Melani C, Sangaletti S, Barazzetta FM, Werb Z, Colombo MP. Amino-biphosphonate-mediated MMP-9 inhibition breaks the tumor-bone marrow axis responsible for myeloid-derived suppressor cell expansion and macrophage infiltration in tumor stroma. Cancer Res 2007; 67(23): 11438-46

[http://dx.doi.org/10.1158/0008-5472.CAN-07-1882] [PMID: 18056472]

[73] Heissig B, Hattori K, Dias S, et al. Recruitment of stem and progenitor cells from the bone marrow niche requires MMP-9 mediated release of kit-ligand. Cell 2002; 109(5): 625-37. [http://dx.doi.org/10.1016/S0092-8674(02)00754-7] [PMID: 12062105]

[74] Parker KH, Sinha P, Horn LA, et al. HMGB1 enhances immune suppression by facilitating the differentiation and suppressive activity of myeloid-derived suppressor cells. Cancer Res 2014; 74(20): 5723-33. [http://dx.doi.org/10.1158/0008-5472.CAN-13-2347] [PMID: 25164013]

[75] Richard SAXL-H, Yun J-X, Shanshan Z, Jiang Y-Y, Wang J, Su Z-LXH-X. Carcinogenic and therapeutic role of High-Mobility Group Box 1 in Cancer: Is it a cancer facilitator, a cancer inhibitor or both? World Cancer Res J 2017; 4(3): e919.

[76] Richard SA, Zheng S, Su Z, Gao J, Xu H. The pivotal neuroinflammatory, therapeutic and neuroprotective role of alpha-mangostin. J Neurol Res 2017; 7(4-5): 67-79.

[http://dx.doi.org/10.14740/jnr455w]

[77] Wang H, Bloom O, Zhang M, et al. HMG-1 as a late mediator of endotoxin lethality in mice. Science 1999; 285(5425): 248-51. [http://dx.doi.org/10.1126/science.285.5425.248] [PMID: 10398600]

[78] Richard SA, Min W, Su Z, Xu H-X. Epochal neuroinflammatory role of high mobility group box 1 in central nervous system diseases. AIMS Mol Sci 2017; 4(2): 185-218.

[http://dx.doi.org/10.3934/molsci.2017.2.185]

[79] Richard SA, Jiang Y, Xiang LH, et al. Post-translational modifications of high mobility group box 1 and cancer. Am J Transl Res 2017; 9(12): 5181-96. [PMID: 29312476]

[80] Seidu RA, Wu M, Su Z, Xu H. Paradoxical role of high mobility group box 1 in glioma: A suppressor or a promoter? Oncol Rev 2017; 11(1): 325. [http://dx.doi.org/10.4081/oncol.2017.325] [PMID: 28382190]

[81] Tang D, Kang R, Zeh HJ, Lotze MT. High-mobility group box 1 and cancer. Biochimica et Biophysica Acta (BBA)-. Gene Regulatory Mechanisms 2010; 1799(1): 131-40 
[82] Richard SA, Sackey M, Su Z, Xu H. Pivotal neuroinflammatory and therapeutic role of high mobility group box 1 in ischemic stroke. Biosci Rep 2017; 37(6): BSR20171104. [http://dx.doi.org/10.1042/BSR20171104] [PMID: 29054968]

[83] Gardella S, Andrei C, Ferrera D, et al. The nuclear protein HMGB1 is secreted by monocytes via a non-classical, vesicle-mediated secretory pathway. EMBO Rep 2002; 3(10): 995-1001. [http://dx.doi.org/10.1093/embo-reports/kvf198] [PMID: 12231511]

[84] Richard SA, Min W, Su Z, Xu H. High mobility group box 1 and traumatic brain injury. J Behav Brain Sci 2017; 7(02): 50. [http://dx.doi.org/10.4236/jbbs.2017.72006]

[85] Peltz ED, Moore EE, Eckels PC, et al. HMGB1 is markedly elevated within 6 hours of mechanical trauma in humans. Shock 2009; 32(1): 17-22. [http://dx.doi.org/10.1097/SHK.0b013e3181997173] [PMID: 19533845]

[86] Schiraldi M, Raucci A, Muñoz LM, et al. HMGB1 promotes recruitment of inflammatory cells to damaged tissues by forming a complex with CXCL12 and signaling via CXCR4. J Exp Med 2012; 209(3): 551-63. [http://dx.doi.org/10.1084/jem.20111739] [PMID: 22370717]

[87] Sims GP, Rowe DC, Rietdijk ST, Herbst R, Coyle AJ. HMGB1 and RAGE in inflammation and cancer. Annu Rev Immunol 2010; 28: 367-88. [http://dx.doi.org/10.1146/annurev.immunol.021908.132603] [PMID: 20192808]

[88] Li W, Wu K, Zhao E, et al. HMGB1 recruits myeloid derived suppressor cells to promote peritoneal dissemination of colon cancer after resection. Biochem Biophys Res Commun 2013; 436(2): 156-61. [http://dx.doi.org/10.1016/j.bbrc.2013.04.109] [PMID: 23707808]

[89] Su Z, Ni P, She P, et al. Bio-HMGB1 from breast cancer contributes to M-MDSC differentiation from bone marrow progenitor cells and facilitates conversion of monocytes into MDSC-like cells. Cancer Immunol Immunother 2017; 66(3): 391-401. [http://dx.doi.org/10.1007/s00262-016-1942-2] [PMID: 27987020]

[90] Yang H, Ochani M, Li J, et al. Reversing established sepsis with antagonists of endogenous high-mobility group box 1. Proc Natl Acad Sci USA 2004; 101(1): 296-301. [http://dx.doi.org/10.1073/pnas.2434651100] [PMID: 14695889]

[91] Bunt SK, Sinha P, Clements VK, Leips J, Ostrand-Rosenberg S. Inflammation induces myeloid-derived suppressor cells that facilitate tumor progression. J Immunol 2006; 176(1): 284-90.

[http://dx.doi.org/10.4049/jimmunol.176.1.284] [PMID: 16365420]

[92] Sha Y, Zmijewski J, Xu Z, Abraham E. HMGB1 develops enhanced proinflammatory activity by binding to cytokines. J Immunol 2008; 180(4): 2531-7. [http://dx.doi.org/10.4049/jimmunol.180.4.2531] [PMID: 18250463]

[93] Bianchi ME, Manfredi AA. High-mobility group box 1 (HMGB1) protein at the crossroads between innate and adaptive immunity. Immunol Rev 2007; 220(1): 35-46. [http://dx.doi.org/10.1111/j.1600-065X.2007.00574.x] [PMID: 17979838]

[94] Dolcetti L, Peranzoni E, Ugel S, et al. Hierarchy of immunosuppressive strength among myeloid-derived suppressor cell subsets is determined by GM-CSF. Eur J Immunol 2010; 40(1): 22-35. [http://dx.doi.org/10.1002/eji.200939903] [PMID: 19941314]

[95] Demetri GD, Griffin JD. Granulocyte colony-stimulating factor and its receptor. Blood 1991; 78(11): $2791-808$. [PMID: 1720034]

[96] Price TH, Chatta GS, Dale DC. Effect of recombinant granulocyte colony-stimulating factor on neutrophil kinetics in normal young and elderly humans. Blood 1996; 88(1): 335-40. [PMID: 8704192]

[97] Nefedova Y, Nagaraj S, Rosenbauer A, Muro-Cacho C, Sebti SM, Gabrilovich DI. Regulation of dendritic cell differentiation and antitumor immune response in cancer by pharmacologic-selective inhibition of the janus-activated kinase 2 /signal transducers and activators of transcription 3 pathway. Cancer Res 2005; 65(20): 9525-35. [http://dx.doi.org/10.1158/0008-5472.CAN-05-0529] [PMID: 16230418]

[98] Yang L, Huang J, Ren X, et al. Abrogation of TGF $\beta$ signaling in mammary carcinomas recruits Gr-1+CD11b+ myeloid cells that promote metastasis. Cancer Cell 2008; 13(1): 23-35. [http://dx.doi.org/10.1016/j.ccr.2007.12.004] [PMID: 18167337]

[99] Yang L, DeBusk LM, Fukuda K, et al. Expansion of myeloid immune suppressor Gr+CD11b+ cells in tumor-bearing host directly promotes tumor angiogenesis. Cancer Cell 2004; 6(4): 409-21.

[http://dx.doi.org/10.1016/j.ccr.2004.08.031] [PMID: 15488763]

[100] Hart IR, Fidler IJ. Role of organ selectivity in the determination of metastatic patterns of B16 melanoma. Cancer Res 1980; $40(7)$ : $2281-7$. [PMID: 7388794]

[101] Li H, Han Y, Guo Q, Zhang M, Cao X. Cancer-expanded myeloid-derived suppressor cells induce anergy of NK cells through membranebound TGF- $\beta$ 1. J Immunol 2009; 182(1): 240-9. 
[http://dx.doi.org/10.4049/jimmunol.182.1.240] [PMID: 19109155]

[102] Vincent J, Mignot G, Chalmin F, et al. 5-Fluorouracil selectively kills tumor-associated myeloid-derived suppressor cells resulting in enhanced T cell-dependent antitumor immunity. Cancer Res 2010; 70(8): 3052-61. [http://dx.doi.org/10.1158/0008-5472.CAN-09-3690] [PMID: 20388795]

[103] Suzuki E, Kapoor V, Jassar AS, Kaiser LR, Albelda SM. Gemcitabine selectively eliminates splenic Gr-1+/CD11b+ myeloid suppressor cells in tumor-bearing animals and enhances antitumor immune activity. Clin Cancer Res 2005; 11(18): 6713-21. [http://dx.doi.org/10.1158/1078-0432.CCR-05-0883] [PMID: 16166452]

[104] Condamine T, Ramachandran I, Youn J-I, Gabrilovich DI. Regulation of tumor metastasis by myeloid-derived suppressor cells. Annu Rev Med 2015; 66: 97-110. [http://dx.doi.org/10.1146/annurev-med-051013-052304] [PMID: 25341012]

[105] Zhang C, Wang S, Li J, et al. The mTOR signal regulates myeloid-derived suppressor cells differentiation and immunosuppressive function in acute kidney injury. Cell Death Dis 2017; 8(3): e2695. [http://dx.doi.org/10.1038/cddis.2017.86] [PMID: 28333137]

[106] Zhao T, Du H, Ding X, Walls K, Yan C. Activation of mTOR pathway in myeloid-derived suppressor cells stimulates cancer cell proliferation and metastasis in lal(-/-) mice. Oncogene 2015; 34(15): 1938-48. [http://dx.doi.org/10.1038/onc.2014.143] [PMID: 24882582]

[107] Wang J, Su X, Yang L, et al. The influence of myeloid-derived suppressor cells on angiogenesis and tumor growth after cancer surgery. Int J Cancer 2016; 138(11): 2688-99. [http://dx.doi.org/10.1002/ijc.29998] [PMID: 26756887]

[108] Huang A, Zhang B, Wang B, Zhang F, Fan K-X, Guo Y-J. Increased CD14(+)HLA-DR (-/low) myeloid-derived suppressor cells correlate with extrathoracic metastasis and poor response to chemotherapy in non-small cell lung cancer patients. Cancer Immunol Immunother 2013; 62(9): 1439-51. [http://dx.doi.org/10.1007/s00262-013-1450-6] [PMID: 23760662]

[109] Yu J, Du W, Yan F, et al. Myeloid-derived suppressor cells suppress antitumor immune responses through IDO expression and correlate with lymph node metastasis in patients with breast cancer. J Immunol 2013; 190(7): 3783-97.

[http://dx.doi.org/10.4049/jimmunol.1201449] [PMID: 23440412]

[110] Achberger S, Aldrich W, Tubbs R, Crabb JW, Singh AD, Triozzi PL. Circulating immune cell and microRNA in patients with uveal melanoma developing metastatic disease. Mol Immunol 2014; 58(2): 182-6. [http://dx.doi.org/10.1016/j.molimm.2013.11.018] [PMID: 24370793]

[111] Weide B, Martens A, Zelba H, et al. Myeloid-derived suppressor cells predict survival of patients with advanced melanoma: Comparison with regulatory T cells and NY-ESO-1- or melan-A-specific T cells. Clin Cancer Res 2014; 20(6): 1601-9. [http://dx.doi.org/10.1158/1078-0432.CCR-13-2508] [PMID: 24323899]

[112] Hiratsuka S, Watanabe A, Sakurai Y, et al. The S100A8-serum amyloid A3-TLR4 paracrine cascade establishes a pre-metastatic phase. Nat Cell Biol 2008; 10(11): 1349-55.

[http://dx.doi.org/10.1038/ncb1794] [PMID: 18820689]

[113] Boutté AM, Friedman DB, Bogyo M, Min Y, Yang L, Lin PC. Identification of a myeloid-derived suppressor cell cystatin-like protein that inhibits metastasis. FASEB J 2011; 25(8): 2626-37. [http://dx.doi.org/10.1096/fj.10-180604] [PMID: 21518852]

[114] Kitamura T, Kometani K, Hashida H, et al. SMAD4-deficient intestinal tumors recruit CCR1+ myeloid cells that promote invasion. Nat Genet 2007; 39(4): 467-75. [http://dx.doi.org/10.1038/ng1997] [PMID: 17369830]

[115] Pang Y, Gara SK, Achyut BR, et al. TGF- $\beta$ signaling in myeloid cells is required for tumor metastasis. Cancer Discov 2013; 3(8): 936-51. [http://dx.doi.org/10.1158/2159-8290.CD-12-0527] [PMID: 23661553]

[116] Kuonen F, Laurent J, Secondini C, et al. Inhibition of the Kit ligand/c-Kit axis attenuates metastasis in a mouse model mimicking local breast cancer relapse after radiotherapy. Clin Cancer Res 2012; 18(16): 4365-74. [http://dx.doi.org/10.1158/1078-0432.CCR-11-3028] [PMID: 22711708]

[117] Panni RZ, Sanford DE, Belt BA, et al. Tumor-induced STAT3 activation in monocytic myeloid-derived suppressor cells enhances stemness and mesenchymal properties in human pancreatic cancer. Cancer Immunol Immunother 2014; 63(5): 513-28. [http://dx.doi.org/10.1007/s00262-014-1527-x] [PMID: 24652403]

[118] Yan HH, Pickup M, Pang Y, et al. Gr-1+CD11b+ myeloid cells tip the balance of immune protection to tumor promotion in the premetastatic lung. Cancer Res 2010; 70(15): 6139-49. [http://dx.doi.org/10.1158/0008-5472.CAN-10-0706] [PMID: 20631080]

[119] Schmid MC, Varner JA. Myeloid cells in the tumor microenvironment: Modulation of tumor angiogenesis and tumor inflammation 2010. [http://dx.doi.org/10.1155/2010/201026]

[120] Carmeliet P. Angiogenesis in life, disease and medicine. Nature 2005; 438(7070): 932-6. [http://dx.doi.org/10.1038/nature04478] [PMID: 16355210]

[121] Folkman J, Merler E, Abernathy C, Williams G. Isolation of a tumor factor responsible for angiogenesis. J Exp Med 1971; $133(2)$ : 275-88. 
[http://dx.doi.org/10.1084/jem.133.2.275] [PMID: 4332371]

[122] Hanahan D, Folkman J. Patterns and emerging mechanisms of the angiogenic switch during tumorigenesis. Cell 1996; 86(3): 353-64.

[123] Carmeliet P, Jain RK. Angiogenesis in cancer and other diseases. Nature 2000; 407(6801): 249

[124] Kujawski M, Kortylewski M, Lee H, Herrmann A, Kay H, Yu H. Stat3 mediates myeloid cell-dependent tumor angiogenesis in mice. J Clin Invest 2008; 118(10): 3367-77. [http://dx.doi.org/10.1172/JCI35213] [PMID: 18776941]

[125] Gabrilovich D, Ishida T, Oyama T, et al. Vascular endothelial growth factor inhibits the development of dendritic cells and dramatically affects the differentiation of multiple hematopoietic lineages In Vivo: Presented in part at the keystone symposium "cellular and molecular Biology of Dendritic Cells," Santa Fe, NM, March 3-9, 1998, and at the annual meeting of the American association for cancer research, march 28-april 1, 1998. Blood 1998; 92(11): 4150-66. [PMID: 9834220]

[126] Kusmartsev S, Eruslanov E, Kübler H, et al. Oxidative stress regulates expression of VEGFR1 in myeloid cells: Link to tumor-induced immune suppression in renal cell carcinoma. J Immunol 2008; 181(1): 346-53. [http://dx.doi.org/10.4049/jimmunol.181.1.346] [PMID: 18566400]

[127] Mucha J, Majchrzak K, Taciak B, Hellmén E, Król M. MDSCs mediate angiogenesis and predispose canine mammary tumor cells for metastasis via IL-28/IL-28RA (IFN- $\lambda$ ) signaling. PLoS One 2014; 9(7): e103249. [http://dx.doi.org/10.1371/journal.pone.0103249] [PMID: 25075523]

[128] Vidal-Vanaclocha F, Mendoza L, Telleria N, et al. Clinical and experimental approaches to the pathophysiology of interleukin-18 in cancer progression. Cancer Metastasis Rev 2006; 25(3): 417-34. [http://dx.doi.org/10.1007/s10555-006-9013-3] [PMID: 17001512]

[129] Lin P, DeBusk L, Huang J. et al Expansion of myeloid immune suppressor cells in Tumor-bearing host directly promotes tumor angiogenesis, tumor growth, and metastasis. Ed. Eds.: AACR

[130] Shojaei F, Wu X, Zhong C, et al. Bv8 regulates myeloid-cell-dependent tumour angiogenesis. Nature 2007; 450(7171): 825-31. [http://dx.doi.org/10.1038/nature06348] [PMID: 18064003]

[131] Gabrilovich DI, Chen HL, Girgis KR, et al. Production of vascular endothelial growth factor by human tumors inhibits the functional maturation of dendritic cells. Nat Med 1996; 2(10): 1096-103. [http://dx.doi.org/10.1038/nm1096-1096] [PMID: 8837607]

[132] Kusmartsev S, Cheng F, Yu B, et al. All-trans-retinoic acid eliminates immature myeloid cells from tumor-bearing mice and improves the effect of vaccination. Cancer Res 2003; 63(15): 4441-9. [PMID: 12907617]

[133] Ozao-Choy J, Ma G, Kao J, et al. The novel role of tyrosine kinase inhibitor in the reversal of immune suppression and modulation of tumor microenvironment for immune-based cancer therapies. Cancer Res 2009; 69(6): 2514-22. [http://dx.doi.org/10.1158/0008-5472.CAN-08-4709] [PMID: 19276342]

[134] Ko JS, Zea AH, Rini BI, et al. Sunitinib mediates reversal of myeloid-derived suppressor cell accumulation in renal cell carcinoma patients. Clin Cancer Res 2009; 15(6): 2148-57.

[http://dx.doi.org/10.1158/1078-0432.CCR-08-1332] [PMID: 19276286]

[135] Ugel S, Delpozzo F, Desantis G, et al. Therapeutic targeting of myeloid-derived suppressor cells. Curr Opin Pharmacol 2009; 9(4): 470-81. [http://dx.doi.org/10.1016/j.coph.2009.06.014] [PMID: 19616475]

[136] De Santo C, Serafini P, Marigo I, et al. Nitroaspirin corrects immune dysfunction in tumor-bearing hosts and promotes tumor eradication by cancer vaccination. Proc Natl Acad Sci USA 2005; 102(11): 4185-90. [http://dx.doi.org/10.1073/pnas.0409783102] [PMID: 15753302]

[137] Talmadge JE, Hood KC, Zobel LC, Shafer LR, Coles M, Toth B. Chemoprevention by cyclooxygenase-2 inhibition reduces immature myeloid suppressor cell expansion. Int Immunopharmacol 2007; 7(2): 140-51. [http://dx.doi.org/10.1016/j.intimp.2006.09.021] [PMID: 17178380]

\section{(C) 2018 Seidu A. Richard.}

This is an open access article distributed under the terms of the Creative Commons Attribution 4.0 International Public License (CC-BY 4.0), a copy of which is available at: (https:/creativecommons.org/licenses/by/4.0/legalcode). This license permits unrestricted use, distribution, and reproduction in any medium, provided the original author and source are credited. 